\title{
Sujeito Pronominal nos Quadrinhos
}

Pronominal subject in the comics

\author{
Rita do Carmo Polli Silva*
}

\section{INTRODUÇÃO}

Autores como Lira (1988), Duarte (1993), Monteiro (1994), Menon (1994; 1996b), Botassini (1998), entre outros, têm demonstrado que o sujeito pronominal está sendo cada vez mais preenchido no português do Brasil (doravante PB) em situações muito distantes daquelas previstas pela Gramática Tradicional (doravante GT).

A grande maioria dos trabalhos variacionistas apresenta corpus constituídos com dados da língua oral. Lira (1988) e Duarte (1993) se diferenciam por apresentarem análise do PB a partir de ocorrências da língua escrita. Esta analisou peças de teatro e aquela, cartas pessoais. O trabalho ora apresentado tem como objetivo examinar um recorte do PB usado nas histórias em quadrinhos (doravante $\mathrm{HQ}$ ), mais especificamente a Pato Donald, publicada no Brasil a partir de 1950 pela Editora Abril, o que possibilita examinar o comportamento do sujeito pronominal em uma análise em tempo real de curta duração.

Tendo em vista que a pesquisa teve início em 2003, decidiu-se por selecionar as revistas editadas nos anos de final três para comporem a amostra: 2003, 1993, 1983, 1973, 1963 e as 21 primeiras edições, de 1950 a 1952 (doravante referidas como 1950/52), haja vista a impossibilidade de encontrar exemplares disponíveis de 1953. O acesso aos números iniciais

Doutoranda em Estudos Lingüísticos da UFPR. 
foi possível porque estes foram republicados em Edição Especial de Aniversário (fac-similar) na década de 1970. Decidiu-se ainda dividir a amostra do ano de 2003 em duas partes, uma composta por revistas de 2003 e a outra por edições do ano de conclusão da pesquisa para obtenção de ocorrências mais recentes, no caso, outubro de 2004. As edições consultadas, num total de 138 revistas, foram obtidas através de empréstimo especial junto à Gibiteca de Curitiba, Diretoria de Patrimônio da Fundação Cultural de Curitiba e Biblioteca Pública do Paraná e muitos adquiridos em sebos da capital paranaense.

Para a composição do corpus desta pesquisa optou-se por analisar somente as pessoas gramaticais referentes ao locutor e ao interlocutor conforme Benveniste (1976), ou seja, a primeira e a segunda pessoa do singular e do plural. Os pronomes você( $(S)$ e o a gente, apesar de não constarem no paradigma dos pronomes pessoais das GTs e na grande maioria das gramáticas pedagógicas, foram acrescentados nesta pesquisa por estarem presentes na língua, além de já constarem como pronomes numa vasta bibliografia de análise do PB. Estendeu-se, desta forma, o número de pronomes a serem analisados neste estudo, haja vista que na primeira e na segunda pessoa há: eu, tu/vocêl, nós/a gente, vocês.

De acordo com a gramática gerativa o português é uma língua pro-drop (de sujeito nulo), mas está perdendo este parâmetro. Segundo Silva (1996), existem algumas línguas que permitem a elipse do pronome sujeito de uma sentença e outras onde essa possibilidade não existe. Como exemplo do primeiro caso temos o italiano e do segundo, o francês.

\section{A PESQUisa}

Os grupos de fatores lingüísticos arrolados para esta pesquisa foram: pessoa verbal, tempo e modo verbal e tipos de frases e um extralingüístico: ano de publicação. Os dados foram submetidos ao pacote Varbrul e o número total de ocorrências da amostra das revistas do nosso corpus é de 19.980 , sendo que o primeiro grupo a ser analisado, as pessoas verbais, apresenta um total de 19.872 ocorrências devido a 108 dados referentes a sujeitos não recuperáveis, ou seja, sujeitos implícitos cujos contextos não permitiram afirmar serem elipses de você ou senhor(a). 


\subsection{As Pessoas Verbais}

O grupo selecionado pelo programa como mais relevante foi o das pessoas verbais e os resultados podem ser observados na tabela abaixo:

TABELA 1 - PREENCHIMENTO DOS PRONOMES SUJEITOS (INPUT .27).

\begin{tabular}{c|c|c|c}
\hline PRONOME & APL./TOTAL & $\%$ & P.R. \\
\hline Eu & $2.799 / 12.212$ & 23 & .42 \\
\hline Tu & $7 / 25$ & 28 & .60 \\
\hline Você & $2.103 / 3.143$ & 67 & .87 \\
\hline Nós & $248 / 3.374$ & 7 & .18 \\
\hline A gente & $289 / 292$ & 99 & 1.00 \\
\hline Vocês & $467 / 826$ & 57 & .82 \\
\hline TOTAIS & $5.913 / 19.872$ & 30 & - \\
\hline
\end{tabular}

De modo geral percebe-se que as HQ aqui analisadas são bastante conservadoras, pois apresentam input .27 , o que nos permite dizer que, apesar de a intenção do editor ${ }^{1}$ ser a de simular a fala, o resultado se assemelha aos de corpus constituídos de língua escrita. Em porcentagem, Lira (1988) encontrou $22 \%$ de preenchimento, enquanto as HQ que compõem esta pesquisa apresentaram $30 \%$.

A evolução dos pesos relativos em tempo real mostra um lento, mas gradativo aumento do preenchimento do pronome sujeito. Nas HQ Pato Donald produzidas nos últimos 54 anos o peso relativo sobe .13, de $.45 \mathrm{em}$ 1950/52, número que revela uma tendência à omissão, para .58 em 2003/ 04, índice revelador de uma inclinação ao preenchimento desta categoria. 0 diagrama desta evolução pode ser observado com mais detalhes no Gráfico 1, na seqüência:

Gráfico 1 - Evolução dos Pesos Relativos do PREENCHIMENTO DO PRONOME SUJEITO EM TEMPO REAL.

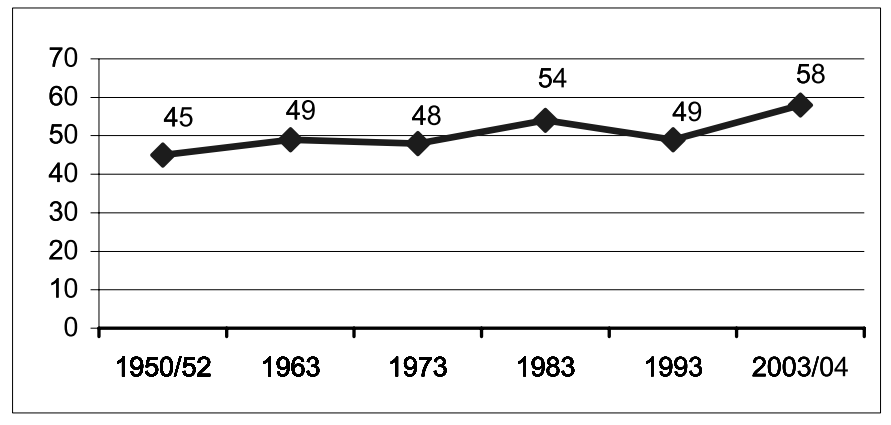

Segundo a Editora Abril "é convenção universal no ocidente que os balões de diálogo simulem a fala" - informação obtida via e-mail. 
$O$ traçado dos pesos relativos apresenta-se em forma de "S" o que é, segundo MENON (2003), característica da mudança, e finaliza em ascensão, o que é um indicativo de que há uma tendência do preenchimento a se manter em elevação.

Ao observamos as pessoas verbais separadamente constatamos que o comportamento delas é diferente entre si. A primeira do singular difere das demais inicialmente pelo elevado número de ocorrências: $80 \%$ do total do corpus, resultado que corrobora os de outras pesquisas variacionistas. Independente da origem da amostra o pronome eu tem se mostrado o mais produtivo. Duarte (1995) de 1.416 dados obteve 631 casos e Botassini (1998), 21.334 em um corpus constituído de 24.181 ocorrências. Menon (1994; 1996) também constatou um número maior de ocorrências deste pronome. Segundo Paredes da Silva (1991, p. 92), que também o encontrou em um número superior de ocorrências, isso ocorre porque a primeira pessoa do singular é a mais central, a mais freqüente como sujeito, enquanto a segunda é menos comum por ser periférica, permanecendo menos no discurso. Monteiro (1994) justifica sua alta ocorrência fazendo referência ao ego-antropocentrismo do discurso, pelo qual as pessoas tendem a falar mais de si mesmas do que de outros e de outras coisas.

Nesta pesquisa temos números gerais que mostram as primeiras pessoas canônicas (eu/nós) com tendência à omissão, característica oposta a das segundas. Em porcentagem os números revelam $80 \%$ de ausências do sujeito com as primeiras pessoas (exceto com o a gente, analisado abaixo) e $35 \%$ para as segundas. Estes números, alto para uma pessoa e baixo para outra, corroboram resultados encontrados em corpus distintos. Paredes da Silva (1991) encontrou $77 \%$ de ausência para as primeiras pessoas canônicas e 30\% para as segundas, em corpus de língua escrita. Em dados de língua falada a segunda pessoa também apresenta preenchimento bastante elevado, Monteiro (1994) encontrou números superiores a $80 \%$.

As pessoas analisadas separadamente possibilitam visualizar que a resistência maior ao preenchimento se deve ao pronome nós, pois a primeira pessoa do singular apresentou leve tendência à omissão do sujeito pronominal, com peso relativo .42. Apesar de o peso relativo apresentar um favorecimento ao não-preenchimento, .42, para uma língua de sujeito nulo, é relativamente alto. Não são muitas, mas há situações com o pronome de primeira pessoa do singular preenchido repetidamente, sem que isto tenha sido feito para desambigüisar ou destacar o sujeito, como orienta a GT. No exemplo abaixo, excetuando o sujeito do verbo ter, antecedido da palavra mesma, que parece favorecer o preenchimento, os demais poderiam estar implícitos, como o primeiro: 
(1) Já vi que, se eu quiser fazer algo direito, como eu quero, eu mesma tenho de fazê-lo! (EDIÇÃo ESPECIAL de julho de 1963).

Neste diálogo ocorre um preenchimento diante de infinitivo e outro antes do presente do indicativo. o terceiro eu preenchido não foi considerado como ocorrência por ter seu uso previsto pela GT, usado para dar ênfase: $e u$ mesma, não há como eliminá-lo, a não ser eliminando junto a palavra mesma. Situação enfática também se vê na seqüência abaixo:

(2) O que eu preciso é de uma história! E como você tem me azucrinado por uma chance pra ser repórter, eu vou lhe dar esta chance agora! (REVISTA 2258, de 2003).

Os dois pronomes eu acima poderiam estar implícitos, pois estão diante de um verbo no presente do indicativo, cuja desinência é bem marcada. Isto se verifica também com o pretérito perfeito do indicativo e o futuro do presente, os três apresentaram 18, 19 e 23\% de preenchimento, respectivamente. Nos demais tempos e modos a desinência coincide com a de outros pronomes, o que possibilita um preenchimento maior para evitar ambigüidades. Cruzando resultados foi possível verificar que o preenchimento de fato é mais freqüente nestes casos, o que varia de $59 \%$ (futuro do pretérito) a $75 \%$ (imperfeito do subjuntivo). Na frase abaixo o presente do subjuntivo apresenta sujeito preenchido para eliminar interpretação ambígua, já que esse tempo verbal não apresenta flexões bem marcadas em todas as pessoas:

(3) E que espera que eu faça? Que eu dê pulos de alegria? (REVISTA 596, de 1963).

Já a primeira pessoa do plural apresentou peso relativo .18, mostrando uma resistência bem maior ao preenchimento. Ao contrário do singular, o pronome nós apresenta desinência bem marcada em todos os tempos e modos verbais (-mos), de maneira que as 248 ocorrências de pronome explícito poderiam ser elipses e não o são. Inclusive o único caso de gerúndio não preenchido da amostra é uma elipse deste pronome:

(4) Bem... devolvendo a orquídea, podemos ir embora! (REVISTA n. 1, de 1950). 
A segunda pessoa do singular (você), neste corpus, tende a apresentar mais o pronome sujeito preenchido do que o plural (vocês), com pesos relativos de .87 e .82 respectivamente. Esta forte tendência ao preenchimento possivelmente se deva à desinência não marcada, portanto não exclusiva destas pessoas verbais, apresentadas em todos os tempos e modos. Monteiro (1994) obteve resultados que também indicaram um preenchimento maior com o singular (68\%) do que com o plural (89\%).

O que chama a atenção na Tabela 1 é a segunda pessoa canônica, o tu. o que temos neste caso é uma inversão entre porcentagem e peso relativo, pois o pronome apresenta $28 \%$ de preenchimento, com tendência de .60. Neste corpus as ocorrências deste pronome estão restritas aos três primeiros números da revista (em 1950). A partir da revista de número 04 não há mais nenhuma ocorrência da segunda pessoa canônica ${ }^{2}$, inclusive, na edição de número 10 , de 1951, página 32, uma personagem conjuga o verbo gostar usando o pronome você como segunda pessoa:

(5) Eu gosto de milho! Você gosta de milho! Nós gostamos de milho!

O pronome de primeira pessoa a gente apresentou preenchimento categórico, apesar de, neste conjunto de dados, haver três casos de sujeito não-preenchidos aos quais o programa não atribuiu peso. Esta tendência acentuada nesta direção era previsível uma vez que a forma verbal que se compatibiliza com este pronome é de morfema número-pessoal não marcado. A elipse do sujeito a gente se dá em situações bem específicas: as três ocorrências apresentaram-no expresso na sentença imediatamente anterior. Os tempos e modos verbais que mais propiciam o uso deste pronome são o presente do indicativo, com $52 \%$ das ocorrências, seguido pelo infinitivo com $24,4 \%$, como na frase abaixo:

(6) Deixe a gente experimentar nossas sementes!

o Gráfico 2, na continuação, permite visualizar a trajetória do pronome, em todos os usos, com picos altos e uma curva terminando em ângulo bastante favorecedor à ascensão para a marcação de primeira pessoa do plural, enquanto a curva da referência indeterminada finaliza em zero.

\footnotetext{
A segunda pessoa do plural canônica (vós) apresentou uma única ocorrência (Revista 2276, de 2003) e não recebeu codificação: Vós ireis vos arrepender do dia em que entrastes aqui! A personagem que utilizou esta forma, na fala imediatamente anterior, e em outras, usou a segunda pessoa vocês: Posso levar vocês até o outro lado por uma moeda de ouro! 
GRÁFICO 2 - O PRONOME $A$ GENTE E SUA REFERÊNCIA, EM NÚMEROS ABSOLUTOS.

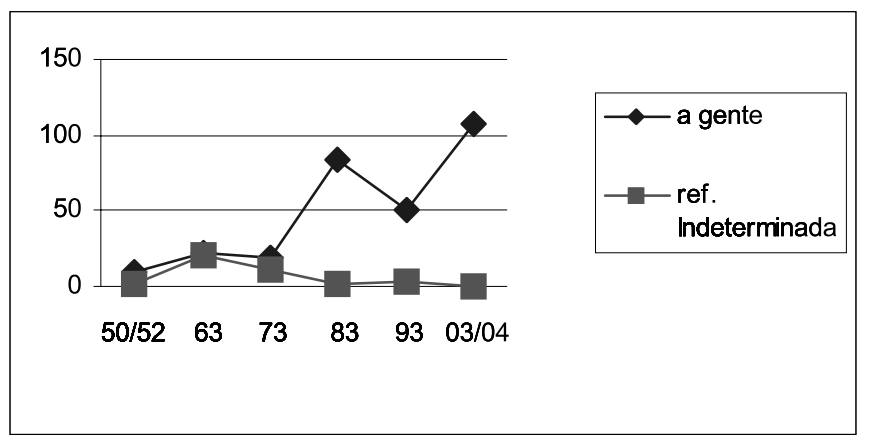

No primeiro período temos 10 ocorrências do pronome e apenas duas indeterminações, o que passa a representar quase a totalidade dos casos (21 indeterminações para 22 ocorrências) em 1963. A partir daí a indeterminação do pronome a gente mostra-se em queda: 11 para 19 ocorrências em 1973, 2 para 84 em 1983, 3 para 50 em 1993 e finalmente assume a função de primeira pessoa do plural com 107 ocorrências em 2003/04. Em outras palavras, dos 292 dados do pronome a gente, somente 39 são de referência indeterminada, $13 \%$ dos casos, todos anteriores a 2003/ 04, o que nos mostra que este pronome, neste corpus, assumiu a função de primeira pessoa do plural.

Esta trajetória vem confirmar os passos de sua gramaticalização. Segundo Omena (1996, p. 190) provavelmente o a gente substituindo o nós e perdendo sua referência indeterminadora tenha tido origem na necessidade de contrapor uma referência precisa a uma imprecisa, na primeira pessoa do plural. Esta ascensão apresentada pelo pronome a gente na língua escrita é mais significativa em corpus de língua oral. Em Silva (2003b) encontrei apenas 7 ocorrências do pronome em 699 dados em um corpus constituído de 77 produções escolares. Em contrapartida, Botassini (1998) em um estudo sobre o preenchimento pronominal na primeira pessoa, eu/nós, encontrou um número maior de a gente do que do plural canônico: 3.717 ocorrências (todas explícitas) para 2.847 do nós. Percebe-se uma tendência maior do uso do pronome a gente na língua falada, normalmente menos formal, enquanto na língua escrita o pronome mostra um uso mais moderado, mas em crescimento, conforme Lira (1988) e Freitas (1991). Não houve, em todo o corpus, nenhum caso de uso do pronome nós com referência indeterminada, 
o que também corrobora os resultados de Omena (1996) que afirma ser o a gente a forma preferida ${ }^{3}$ para a referência mais geral, indeterminadora.

Em contrapartida o pronome nós parece estar fazendo o caminho inverso do a gente na referência da primeira pessoa do plural, conforme mostra o gráfico abaixo, no qual foram utilizados números absolutos para melhor visualização ${ }^{4}$.

\section{GrÁfico 3 - Uso dos PRonomes Nós e A GENTE,} POR DÉCADA.

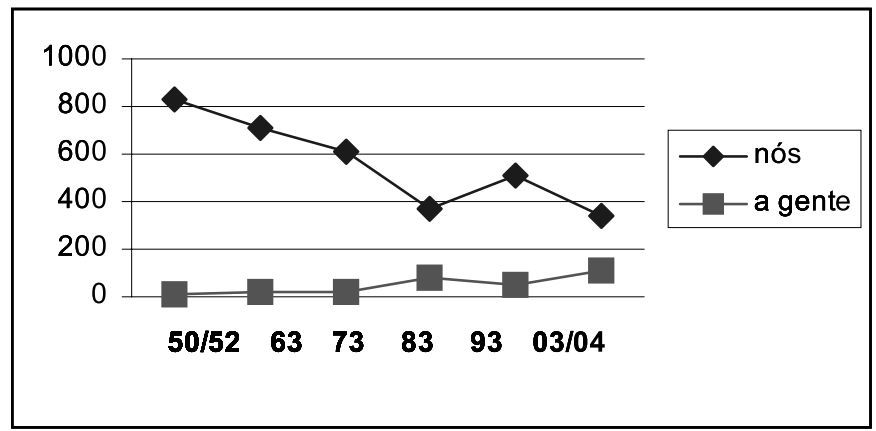

Embora o número de ocorrências seja bastante diferente entre os pronomes e entre as décadas o que se percebe é um acréscimo no uso do a gente enquanto ocorre um decréscimo com o pronome nós. O que se percebe acima é um ligeiro aumento no uso do pronome a gente no período de 1983 e um indicativo de ascensão ao final da amostra. Notória é a queda no uso do pronome nós. Em 1950/52 ele era usado oitenta vezes mais do que o a gente e em 2003/04 esta correspondência caiu para três por um ${ }^{5}$.

Não houve nenhum caso em todo o corpus de variações estigmatizados como "a gente fizemos" ou "nós fez". Omena (1996, p. 311) e Botassini (1998) destacam que encontraram alguns casos do pronome $a$ gente com o verbo conjugado na primeira pessoa do plural canônica, em dados de língua falada. O fato de não haver neste corpus nenhuma ocorrência desses casos revela que as concordâncias estão de acordo com os cânones gramaticais, característica do conservadorismo mais inerente ao texto escrito.

\footnotetext{
Terminologia da autora.

A linha destes pronomes, traçada em porcentagem, pode ser vista no Gráfico 5 , adiante, juntamente com os demais pronomes da amostra.

Em 1950/52 o pronome nós representava $18 \%$ das ocorrências do período, em $1963,22 \%$, em $1973,17 \%$, em $1983,14 \%$, em $1983,15 \%$ e em $2003 / 04,11 \%$. Com o pronome a gente os números são os seguintes: 1950/52/0,22\%, 1963/0,70\%, 1973/0,53\%, 1983/3,2\%, $1993 / 1,5 \%$ e $2003 / 04 / 3,6 \%$.
} 
Quanto à integração da nova forma ao sistema, este corpus e outros já citados, mostraram que é um fato. No tocante à incorporação de formas relacionadas ao pronome nós, neste conjunto de dados há três exemplos de a gente com o possessivo nosso:

(7) A gente pode emprestar o dinheiro do nosso cofrinho! (REVISTA 1644, de 1983).

(8) A gente só queria ajudar nosso tio! (REVISTA 2011, de 1993).

(9) Sugiro que a gente recomece nosso emagrecimento já! (REVISTA 2011, de 1993).

Esses resultados em tempo real mostram que o processo de gramaticalização do pronome a gente está em fase final, pois, além de já estar integrado ao paradigma pronominal do $\mathrm{PB}$, incorporou o possessivo nosso, relacionado à variante nós, segundo Menon (2003, p. 104).

o preenchimento geral dos pronomes sujeitos no corpus foi de $30 \%$, índice que favorece grandemente a elipse. Em dados de língua falada os índices são bastante diferentes, cerca de $60 \%$, Botassini (1998), por exemplo, encontrou, num corpus constituído a partir das entrevistas do VARSUL, $61 \%$. O índice baixo desta amostra indica que a $\mathrm{HQ}$ em questão não é representação da língua oral; apesar da intenção de simular a fala e do senso comum, inclusive de muitos professores de português, que condenam sua leitura com a justificativa de que elas representam a fala, e, portanto, não são indicadas para a leitura dos alunos. O fato de ser escrito e revisto, e esta revisão estar voltada à GT, está fazendo diferença.

Este resultado vem confirmar que a língua escrita realmente apresenta um índice de preenchimento bem menor do que a língua falada. De qualquer forma, como já mencionado anteriormente, este índice é considerado alto para uma língua cuja orientação é, excetuando casos específicos, não empregar o sujeito pronominal.

\subsection{TEMPO E MOdo VERBAL}

Os tempos e os modos verbais de maior incidência no corpus são o presente e o pretérito perfeito do indicativo, apresentando .46 e .52 de tendência ao preenchimento da regra variável, respectivamente. Há, portanto, um ligeiro favorecimento no sentido de preencher o sujeito pronominal com o pretérito perfeito do indicativo. A tabela abaixo traz os números percentuais e os pesos relativos de cada tempo e modo verbal. 
TABEla 2 - PREENCHIMENTO DO PRONOME SUJEITO A PARTIR DO GRUPO DE FATORES TEMPO E MODO VERBAL.

\begin{tabular}{lrrc}
\hline \multicolumn{1}{c}{ TEMPO E MODO VERBAL } & APL./TOTAL & $\%$ & P.R. \\
\hline Presente do indicativo & $3.429 / 13.510$ & 25 & .46 \\
\hline Futuro do presente & $395 / 1.660$ & 24 & .50 \\
\hline Pretérito perfeito do ind. & $930 / 2.722$ & 34 & .52 \\
\hline Infinitivo & $383 / 731$ & 52 & .57 \\
\hline Futuro do subjuntivo & $32 / 102$ & 31 & .58 \\
\hline Presente do subjuntivo & $69 / 136$ & 51 & .70 \\
\hline Futuro do pretérito & $350 / 600$ & 58 & .79 \\
\hline Pretérito imperfeito do ind. & $234 / 384$ & 61 & .83 \\
\hline Imperfeito do subjuntivo & $86 / 129$ & 67 & .87 \\
\hline Gerúndio & $5 / 6$ & 83 & .96 \\
\hline TOTAIS & $5.913 / 19.980$ & 30 & - \\
\hline
\end{tabular}

Aparentemente as desinências parecem não estar inibindo o preenchimento do sujeito. Por outro lado, se observarmos os outros tempos e modos verbais veremos que os pesos relativos apontam um grande favorecimento ao preenchimento do sujeito, exceto com ofuturo do presente, ou seja, as desinências bem marcadas permitem o preenchimento do sujeito em menor escala.

o pretérito perfeito do indicativo tem $34 \%$ das ocorrências preenchidas. $O$ que o programa nos mostra é que a tendência de ocorrer um sujeito pronominal explícito com ele é maior do que a tendência à elipse, pois os pronomes você, vocês e a gente apresentam porcentagem de preenchimento, neste caso, de $65 \%, 62 \%$ e $95 \%$ respectivamente. Com este tempo e modo verbal somente os pronomes de primeira pessoa canônicos apresentaram baixo percentual de preenchimento por serem bem marcados: eu $23 \%$ e nós $25 \%$. Este é o único tempo verbal em que o pronome nós apresentou porcentagem de preenchimento maior do que o da primeira pessoa do singular, revelando-se como um contexto favorecedor do preenchimento da primeira pessoa do plural, canônica, na posição de sujeito.

O mesmo pode ser observado com of futuro do subjuntivo, houve uma ausência maior do pronome, mas a tendência é que esta categoria seja mais preenchida do que elíptica com este tempo e modo verbal. Das 102 ocorrências, 44 têm como sujeito o pronome nós, dos quais $98 \%$ estão elípticos. As outras pessoas apresentaram índices percentuais bem maiores no preenchimento, exceto o pronome você, por isso esta tendência mostrouse mais elevada (eu $56 \%$, vocês $64 \%$ e a gente $100 \%$ ). 
o futuro do presente, também nos mostra uma porcentagem baixa de preenchimento, apenas $24 \%$ dos verbos tiveram os sujeitos preenchidos, mas apesar disso o que a análise nos mostra é nenhuma tendência, o peso relativo é neutro, ou seja, a amostra analisada não aponta o futuro do presente, que é um tempo com marcas desinenciais específicas, como favorecedor ou inibidor da aplicação desta regra variável. Possivelmente esse ponto neutro tenha sido obtido a partir do grande número de ocorrências de primeira pessoa canônica, 1.425, que apresentaram baixa porcentagem de preenchimento, apenas $16 \%$, e o alto índice percentual do pronome $a$ gente e da segunda pessoa, inclusive a canônica, que, apesar do reduzido número de ocorrências, 235, apresentaram preenchimento em $70 \%$ delas.

Some-se a isto o fato de o uso deste tempo e modo verbal estar em franco declínio, o que também constatou Botassini (1998), que encontrou apenas duas ocorrências em um corpus constituído de língua falada. A pesquisadora justifica este reduzido uso afirmando que ofuturo do presente é pouco usado na língua falada, o que corrobora Cunha (1984, p. 439), onde se pode ler a mesma observação. A análise da revista Pato Donald apresenta 1.660 ocorrências, num corpus menor do que o da pesquisadora acima, o que vem somar às outras evidências de que as $\mathrm{HQ}$ não são representação do oral, apesar de tentarem simular a fala.

o presente do subjuntivo também apresentou resultados bastante interessantes, suas porcentagens de preenchimento/não-preenchimento estão bem próximas, $51 / 49 \%$, no entanto a tendência de preenchimento é de .70 . Este tempo e modo verbal apresenta a mesma desinência número-pessoal para a primeira pessoa do singular, $e u$, para a segunda, você e para o pronome a gente (-e), a segunda pessoa do plural também tem desinência idêntica à terceira $(-\mathrm{em})$. Desta forma é previsível a tendência ao preenchimento do sujeito pronominal para evitar interpretações equívocas. O que contribuiu para que a porcentagem de preenchimento ficasse baixa foi o pronome nós, que apresentou 25 dos seus 26 casos com o presente do subjuntivo elípticos.

Todos os demais tempos e modos verbais propiciam o preenchimento do sujeito. Apesar de os números mostrarem esta grande tendência, todos juntos somam 1.850 ocorrências, menos de $10 \%$ da amostra. Quanto ao gerúndio a GT não menciona o fato de esta forma aceitar sujeito pronominal e o corpus apresentou 05 ocorrências de preenchimento ${ }^{6} \mathrm{e}$ uma de ausência, já apresentada acima. Mesmo tendo uma representatividade exígua, $0,03 \%$ da amostra, o que se verifica neste caso é algo não previsto pela GT. 


\subsection{TIPOS DE FRASES}

As frases declarativas afirmativas representam $77 \%$ da amostra, enquanto as interrogativas, $13 \%$ e as negativas, exatos $10 \%$. A distribuição das ocorrências dentro do grupo de fatores tipos de frases pode ser observada abaixo:

TABELA 3 - PREENCHIMENTO do PRONOME SuJEITO A PARTIR DO GRUPO DE FATORES TIPO DE FRASES.

\begin{tabular}{lrcc}
\hline \multicolumn{1}{c}{ TIPOS DE FRASES } & APL. TOTAL & $\%$ & $P . R$. \\
\hline Interrogativa & $961 / 2.501$ & 38 & .34 \\
\hline Declarativa negativa & $524 / 1.998$ & 26 & .49 \\
\hline Declarativa afirmativa & $4.428 / 15.481$ & 29 & .53 \\
\hline TOTAIS & $5.913 / 19.980$ & 30 & \\
\hline
\end{tabular}

Há uma tendência de preenchimento nas frases declarativas afirmativas, que apresentaram peso relativo .53. Das 15.481 ocorrências, 11.053 (71\%) não apresentaram pronome sujeito expresso, mas a análise probabilística mostra peso relativo .53 para o preenchimento, ou seja, houve uma inversão entre as porcentagens e os pesos relativos. As negativas tendem levemente à ausência, com .49, enquanto as interrogativas a propiciam largamente, com .34.

As pessoas verbais que apresentaram alto índice de preenchimento foram as não canônicas ( $16 \%$ do número total das frases afirmativas): você preencheu $78 \%$, vocês, $67 \%$ e o a gente, $99 \%$. As pessoas canônicas apresentaram altos índices de ausências e são responsáveis por $71 \%$ das elipses: $e u / 77 \%$, nós $/ 93 \%$ e tu/81\%. O que se pode perceber é que a desinência verbal bem marcada inibe o preenchimento quando a frase é afirmativa, o que não acontece com os demais tipos de frases.

Os números acima corroboram os resultados de Duarte (1995), que menciona o fato de as frases interrogativas e as negativas propiciarem a ausência do sujeito pronominal. Nas HQ analisadas, quando a frase é interrogativa, os pronomes que apresentam tendência ao preenchimento são o você e o a gente. A primeira pessoa canônica preenche mais a posição de sujeito quando a frase é interrogativa, tendo apresentado pronome explícito em $29 \%$ das ocorrências e o nós, em $8 \%$, os maiores índices de preenchimento destas duas pessoas.

A grande tendência de ausência com as frases interrogativas possivelmente se deva à circunstância de uso, isto é, na grande maioria das situações de indagações o olhar do falante (ou um outro gesto) geralmente 
é dirigido ao seu interlocutor antes da pergunta propriamente dita, o que minimiza as interpretações imprecisas.

(10) Que quer? (REVISTA 13, de 1963).

Este é um diálogo entre o Pateta e o Mickey. O Pateta, neste caso, olha para o Mickey e faz a pergunta. O seu olhar, direcionado ao interlocutor, dispensa o uso do pronome sujeito. $\mathrm{O}$ mesmo acontece na situação abaixo:

(11) Não acha que esse arame está eletrificado? (REVISTA 14, de 1951).

Em circunstâncias como esta não há necessidade de explicitar o pronome sujeito, só há duas pessoas, o verbo achar, conjugado no presente do indicativo, acha, só pode ter como sujeito você, a pessoa com a qual se está conversando, os dois estão sozinhos, portanto, a elipse do sujeito é perfeitamente entendida pela situação. Possivelmente um sujeito explícito nestas circunstâncias serviria para enfatizá-lo, o que também depende da situação. Há ocasiões que a ênfase no pronome lexicalmente desnecessário se dá pela circunstância. Na situação:

(12) O quê? Você andou bebendo? (REVISTA 14, de 1951.)

O preenchimento do sujeito do verbo andar pesa sobre a pergunta. "Andou bebendo?" tem um valor semântico, com o pronome expresso tem outro, ou outros, um deles pode ser "Você, que não bebe, andou bebendo? Você?".

As frases negativas, neste corpus, apresentam peso relativo .51 para a ausência, o que representa uma pequena tendência. Provavelmente a condução do resultado da análise para este lado se deva a primeira pessoa, o pronome $e u$ apresenta $80 \%$ de suas ocorrências com pronomes elípticos e o nós, 94\%. A única pessoa canônica a apresentar tendência ao preenchimento foi o pronome $t u$, que tem apenas três frases com elemento de negação em todo o corpus, destas, duas estão preenchidas. 0 pronome você preencheu $74 \%$ das ocorrências em declarativas negativas, o vocês, $57 \%$ e o a gente $100 \%$ das 26 ocorrências com este tipo de frases. O que pôde ser observado é que quatro pronomes apresentaram preenchimento menor com as negativas do que com as afirmativas. O pronome vocês, apesar de preencher $57 \%$ das suas ocorrências, com as negativas está preenchendo menos do que com as afirmativas, onde preencheu $67 \%$. O singular, você, preencheu $78 \%$ com as afirmativas e $74 \%$ com as negativas. A primeira pessoa canônica apresentou 
o mesmo comportamento, o pronome eu preencheu $23 \%$ com as afirmativas e $20 \%$ com as negativas e o nós, $7 \%$ para $6 \%$, ou seja, para estes pronomes o elemento de negação está funcionando como inibidor do sujeito.

\subsection{ANo DE PubliCAÇÃo - FATOR EXTRALINGÜístico}

Nos períodos analisados tanto a porcentagem de preenchimento quanto a tendência de um sujeito aparecer explícito apresentam crescimento, conforme tabela abaixo:

TABELA 4 - PREENCHIMENTO DO PRONOME SUJEITO A PARTIR DO GRUPO DE FATORES ANO DE PUBLICAÇÃO.

\begin{tabular}{crcc}
\hline ANO DE PUBLICAÇÃO & APL./TOTAL & $\%$ & P.R. \\
\hline $1950 / 52$ & $1.088 / 4.538$ & 24 & .45 \\
\hline 1963 & $826 / 3.127$ & 26 & .49 \\
\hline 1973 & $1.015 / 3.551$ & 29 & .48 \\
\hline 1983 & $879 / 2.547$ & 35 & .54 \\
\hline 1993 & $989 / 3.289$ & 30 & .49 \\
\hline $2003 / 04$ & $1.116 / 2.928$ & 38 & .58 \\
\hline TOTAIS & $5.913 / 19.980$ & 30 & \\
\hline
\end{tabular}

Nos três primeiros percebe-se uma tendência à elipse do pronome sujeito, situação que se inverte em 1983 e 2003/04. No ano de 1983 o peso relativo apresenta um acréscimo de .09 em relação a 1950/52, situação que mostra uma tendência ao preenchimento do pronome sujeito.

Em 1993 esta tendência de preenchimento cai. .05 em relação ao ano anterior. Neste ano é possível ver que, apesar de a porcentagem de ausência ( $70 \%$ ) ser mais que o dobro do preenchimento (30\%), o peso relativo continua próximo do ponto neutro, que é .50 , em outras palavras, apesar do aparente rigor da revisão neste ano o preenchimento ou a ausência tendem a ocorrer quase na mesma proporção.

Os dados da Tabela 4 colocados em gráfico nos permitem verificar um distanciamento invertido nos dois pólos, pois no primeiro período analisado o preenchimento e a ausência apresentam um distanciamento entre si de .10 a favor da ausência e no último esta diferença sobe para .16 para o preenchimento. No período total o preenchimento apresenta um aumento na tendência de aplicação da regra variável de .13 e finaliza de forma ascendente. 


\section{GRÁFICO 4 - COMPORTAMENTO DO PREENCHIMENTO E DA AUSÊNCIA DO SUJEITO PRONOMINAL, A PARTIR DO GRUPO DE FATORES ANO DE PUBLICAÇÃO.}

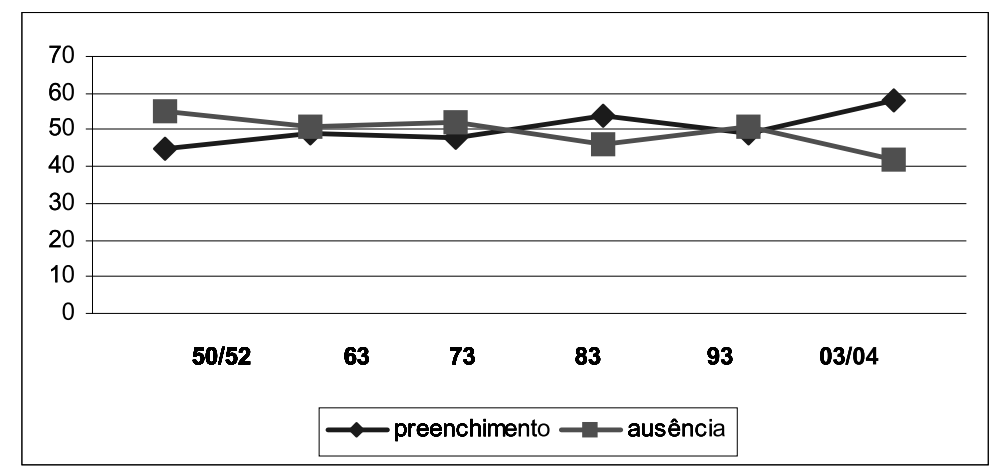

A tendência de preenchimento mais baixa do corpus, apresentada em 1950/52, já é considerada alta para uma língua de sujeito nulo como o PB (.45), segundo a classificação gerativista. Em todos os anos o que se vê é uma porcentagem reduzida de sujeitos preenchidos com uma tendência ao preenchimento relativamente alta. Exceto os três pronomes canônicos $(e u$, $t u$, nós) os demais apresentam índices de preenchimento bastante altos, mas com reduzido número de ocorrências. São 4.261 casos de você/vocês e a gente, com $67 \%$ de pronomes explícitos, enquanto com os pronomes eu, tu e nós são 15.611 dados com $20 \%$ de preenchimento. Estes números resultam em porcentagem baixa e tendência de explicitação do pronome alta, de modo geral, em todos os períodos analisados.

Ponderando cada pronome isoladamente percebe-se que as primeiras pessoas canônicas apresentam uma tendência diacrônica no sentido de um maior preenchimento do sujeito: a do singular (eu) passa de $19 \%$ em 1950/52 para 30\% em 2003/04 e a do plural (nós), que de modo geral explicita muito pouco o sujeito devido a sua sempre presente desinência bem marcada (-mos), apresenta, em média, um crescimento no preenchimento. Muito embora, como já citado, o número de ocorrências deste pronome esteja diminuindo vertiginosamente, dando lugar ao a gente que, perdendo sua referência indeterminadora, assume, neste corpus, função de primeira pessoa do plural e apresenta preenchimento praticamente categórico em suas 292 ocorrências no decorrer dos cinqüenta anos analisados.

Estes percursos podem ser observados no próximo gráfico, que traz a evolução diacrônica de todas as pessoas analisadas na pesquisa, exceto o pronome $t u$, que ocorreu só no ano de 1950 e, portanto, não apresenta variação: 
GRÁFICO 5 - PREENCHIMENTO do SUJEITO PRONOMINAL A PARTIR DA TABULAÇÃo CRUZAda ENTRE OS GRUPOS DE FATORES PESSOA VERBAL E ANO DE PUBLICAÇÃO, EM PORCENTAGEM.

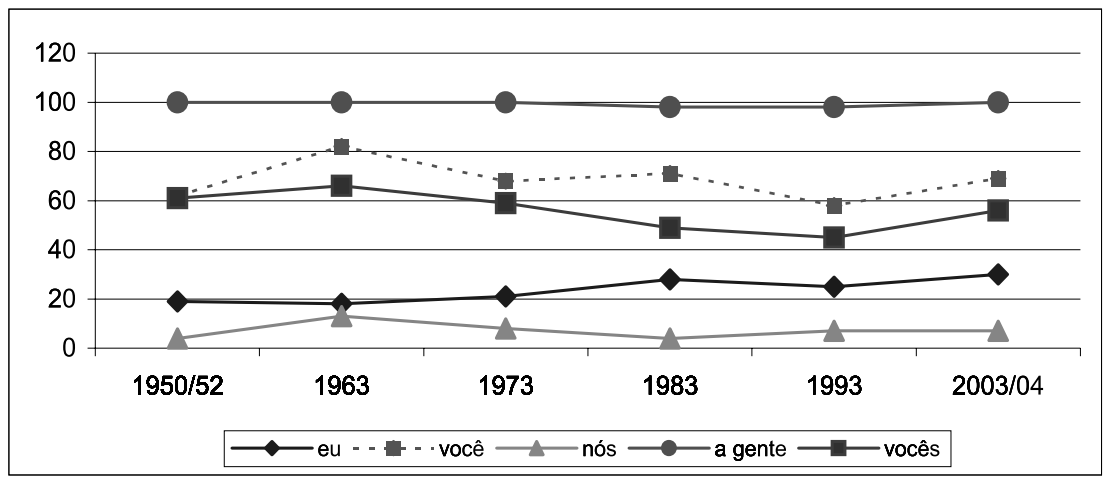

As segundas pessoas: você e vocês apresentam comportamentos distintos entre si. A forma singular apresenta uma média de crescimento no preenchimento do sujeito e a forma plural, uma queda, tendo um percentual de mais ausências em 2003/04 do que em 1950/52. O pronome você apresenta, em 1950/52, 61\% de preenchimento, o que aumenta consideravelmente nos dados de 1963, indo para 82\%, caindo para $68 \%$ em 1973 e subindo novamente em 1983, 71\%. Em 1993 a porcentagem volta a descer, chegando a 58\%, o que aumenta para $69 \%$ no último período analisado, resultando em uma evolução em S, característica da variação.

Esta mesma evolução não é apresentada pela forma pluralizada, o pronome vocês só apresenta crescimento na porcentagem de preenchimento em 1963 e em 2003/04 e a porcentagem deste último período é menor do que nos dois primeiros. Aparentemente, nos dados deste corpus, a segunda pessoa do plural favorece menos o preenchimento do sujeito do que a do singular.

Excetuando os pronomes nós e a gente, ambos representantes da primeira pessoa do plural, e que apresentam uma estabilidade ao final do período, os demais apresentam uma curva para cima, assinalando que, com eles, o preenchimento do sujeito tende a crescer.

Neste gráfico também é possível verificar o que já foi mencionado em situação anterior sobre o comportamento diferenciado do ano de 1993, e aqui também de 1963, possivelmente resultado de uma revisão mais acurada por parte da editora. Especificamente sobre 1963 cito Menon (2003, p. 102) que também observou um comportamento diferente nos dados dos anos 1960 e relembra que, nesta época, o país vivia sob a égide da censura prévia e do cerceamento da livre expressão, o que poderia induzir a uma revisão mais rígida, tanto dos conteúdos quanto da forma. 


\section{CONCLUSÃO}

No cômputo geral dos 19.980 dados analisados obtivemos input .27 para preenchimento do pronome sujeito o que corrobora outros resultados compostos a partir de dados da língua escrita.

As desinências verbais mostraram-se um fator inibidor do preenchimento do sujeito. Já as pessoas verbais apresentaram comportamentos distintos entre si. As primeiras pessoas canônicas tendem a omitir o sujeito pronominal, apesar de terem apresentado índices de preenchimento em elevação no decorrer do período analisado. Estas pessoas apresentam desinências bem marcadas com a maioria dos tempos e modos verbais que compõem a análise, o oposto das segundas pessoas você/vocês e do pronome a gente, desprovidas destas desinências número-pessoal em todos os tempos e modos verbais analisados, e que, por isso, apresentam maiores índices de preenchimento. Em outras palavras, este grupo de fatores mostrou que as desinências parecem ainda representar fator inibidor para o preenchimento do sujeito. Diferença também observada por Paredes da Silva (1991) e Duarte (1993), sendo que esta verificou ainda que os contextos que revelam mais profundamente a mudança são os de segunda pessoa, onde, segundo ela, teve início a redução do paradigma flexional. Monteiro (1994), ao verificar o comportamento diferente entre as pessoas verbais, concluiu que a noção de pessoa do discurso é mais favorecedora do preenchimento que a desinência verbal. $O$ autor encontrou peso relativo de explicitação do sujeito bastante superior para a segunda pessoa do singular, você, em relação ao plural, vocês. Os resultados aqui obtidos corroboram os dos autores acima, inclusive o maior preenchimento pela segunda pessoa do singular.

No tocante ao pronome a gente foi possível verificar etapas da sua gramaticalização. Nos períodos iniciais da análise sua referência indeterminadora era bastante acentuada e o número de ocorrências, reduzido. A análise em tempo real mostrou um uso crescente e o fato de o pronome ter assumido a função de primeira pessoa do plural, perdendo a referência indeterminada. Como último estágio da gramaticalização observaram-se ainda exemplos de seu uso juntamente com o possessivo nosso, forma até então exclusiva da forma canônica, que, em contrapartida apresentou acentuada queda no uso, agora dividido com a forma inovadora. Não foram localizadas no corpus ocorrências de indeterminação do pronome nós, portanto não se pode afirmar que ele está assumindo a referência deixada pelo a gente, mas visualizou-se o seu declínio e possivelmente ele venha a assumir, no futuro, esta função para garantir a sua sobrevivência na língua. 
Também no grupo de fatores tipos de frases os pronomes mostram comportamento diferenciado entre eles. $O$ pronome $e u$ preenche mais o sujeito quando a frase é interrogativa, parece que a entonação da pergunta possibilita um maior preenchimento com a primeira pessoa do singular. Em contrapartida o pronome você, que apresentou, no geral, um alto índice de preenchimento, tende à elipse em frases interrogativas. As frases negativas revelaram uma tendência maior de inibir o preenchimento com os pronomes $e u$, nós, você e vocês. No geral os resultados com as frases negativas e as interrogativas nos permitem afirmar que ambas inibem o preenchimento do pronome.

O grupo de fatores extralingüísticos ano de publicação mostra que, apesar da tendência conservadora do texto escrito, há um aumento em tempo real na aplicação da regra variável objeto deste estudo. Houve um leve aumento nos pesos relativos encontrados entre o primeiro período analisado e o último, o que permite afirmar que está havendo um maior preenchimento do pronome sujeito na língua escrita representada pelas $\mathrm{HQ}$ Pato Donald. A média dos pesos relativos apresentados na análise da variação em tempo real é de .52, tendendo à explicitação pronominal. Este número é bastante significativo, haja vista que as orações que compõem a amostra são simples. Duarte (1993) encontrou um contexto de maior resistência ao preenchimento com este tipo de frases. Isto, posto ao lado dos resultados aqui encontrados, nos revela que a variante inovadora está ocorrendo em situações que antes eram consideradas favorecedoras da elipse, em dados de língua escrita. $O$ fato de o peso relativo estar próximo do ponto neutro significa que o parâmetro pro-drop está, no mínimo, comprometido, ou seja, o PB está deixando de ser uma língua de sujeito nulo.

Esta pesquisa mostrou ainda que as HQ Pato Donald apresentam características conservadoras inerentes aos textos escritos, neste caso um preenchimento maior do sujeito pronominal se comparado aos resultados obtidos a partir de dados de língua oral e um maior uso do futuro sintético, o que também ocorre com menor freqüência na língua falada. A análise em tempo real de curta duração aqui apresentada mostrou que, no tocante ao preenchimento do pronome sujeito, há uma mudança em processo no PB. Este corpus mostrou resultados bem próximos aos obtidos por Lira (1988) e Paredes da Silva (1991), o que põe por terra resquícios de preconceito por parte de alguns pais e professores de língua que insistem em dizer que "gibi" não é leitura recomendável por ser representação da língua oral, como se, sendo, fosse algo impróprio. 


\title{
RESUMO
}

A presente pesquisa foi desenvolvida com base nos pressupostos teóricos e metodológicos da Sociolingüística Variacionista (LABOV, 1972) e teve como foco a variação pronominal no Português Brasileiro, delimitando como objeto de análise os pronomes de primeira (eu, nós, a gente) e segunda pessoa (tu, vós, você, vocês). O corpus analisado foi composto pelas revistas em quadrinhos Pato Donald e compreendeu as edições de 1950 a 1952, 1963, 1973, 1983, 1993 e 2003/ 2004 somando, ao final de todo o processo, 19.980 ocorrências, que foram submetidas ao programa computacional VARBRUL para análise quantitativa e qualitativa dos dados. O estudo teve como principal objetivo a investigação do processo variacional apresentado pela alternância do preenchimento/ não-preenchimento dos pronomes de primeira e segunda pessoa em posição de sujeito, verificando os possíveis condicionamentos lingüísticos e sociais do fenômeno na língua escrita representada pelos quadrinhos. Além da análise da variação estudamos o comportamento dos pronomes nós e a gente separadamente para delinearmos a trajetória de ambos no período. Foram trabalhadas três variáveis lingüísticas, pessoa gramatical, tempo e modo verbal e tipos de frases, e uma social: ano de publicação.

Palavras-chave: Português brasileiro; mudança em tempo real de curta duração; preenchimento do sujeito pronominal.

\begin{abstract}
The present research was developd based on the theoretical and methodological presumptions of the Variationist Sociolinguistics (LABOV, 1972) and focused on the pronominal variation in the Brazilian Portuguese, delimiting as the object of analysis the $1^{\text {st }}\left(e u, n o ́ s, a\right.$ gente) and $2^{\text {nd }}$ person pronouns $(t u, v o c \hat{e}, v o c e \hat{s})$. The corpus analysed is part of the Duck Donald comics and was compounded of the editions of 1950 a 1952 , 1963, 1973, 1983, 1993 e 2003/2004, adding, at the end of the process, 19.980 occurrences whith were submited to the VARBRUL computacional program, for the qualitative and the quantitative analyses of data. The study had as main objective the investigation of the variational process represented by the alternation of the fulfillment/no fulfillment of the pronouns de $1^{\text {st }} \mathrm{e} 2^{\text {nd }}$ person pronouns in the subject position, verifying the possible linguistic conditioning of the phenomenon on written language represented in comics. Besides the variation analyses,
\end{abstract}


SILVA, R. do C. P. SujeIto Pronominal nos Quadrinhos

we also studied the behavior the pronouns nós and a gente separately to draw the trajectory of both in that period of time. We worked with three linguistic variables: the grammatical personal, time and verbal form and types of sentences and three social: sex, classification age and year of publication. Key-words: Brazilian Portuguese; shift in real time of near duration; subject pronominal.

\section{REFERÊNCIAS}

BENVENISTE, Émile. Problemas de lingüística geral. São Paulo: Companhia Editora Nacional, 1976

BOTASSINI, Jacqueline Ortelan M. A elipse do sujeito pronominal na linguagem falada do Paraná: uma análise variacionista. Dissertação (Mestrado) - UFPR, 1998.

CUNHA, Celso F. da. Gramática da Língua Portuguesa. 10. ed. Rio de Janeiro: FAE, 1984.

DUARTE, Maria Eugênia Lamoglia. Do pronome nulo ao pronome pleno: a trajetória do sujeito no português do Brasil. In: ROBERTS, Ian; KATO, Mary (Orgs.). Português Brasileiro - uma viagem diacrônica. 2. ed. Campinas: Unicamp, 1993. p. 107-128.

FREITAS, Judith. Nós e a gente em elocuções formais. Estudos Lingüísticos e Literários, Salvador, n. 11, p. 91-102, 1991.

LIRA, Solange de Azambuja. O sujeito pronominal no português falado e escrito. Itha do Desterro, Florianópolis: UFSC, n. 20, p. 31-43, 1988.

MENON, Odete P. S.; LAMBACH, Jane B.; LANDARIN, Noeli R. X. N. Alternâncias nós e a gente nos quadrinhos, análise em tempo real. In RONCARATI, Claudia; ABRAÇADO, Jussara. Português Brasileiro, contatos lingüísticos, heterogeneidade e história (Orgs.). Rio de Janeiro: 7 Letras, 2003.

. A gente: um processo de gramaticalização. Estudos Lingüísticos, XXV. Anais do XLIII Sem. GEL. UNAERP, Ribeirão Preto, 1996a.

. Aspectos do sistema pronominal relevantes para o ensino básico. João Pessoa. ANPOLL, p. 502-503, $1996 \mathrm{~b}$.

. O sistema pronominal no Brasil. Revista Letras, UFPR, Curitiba, n. 44, 1995.

. Português: língua de sujeito nulo? In: CONGRESSO INTERNACIONAL DA ABRALIN, I., Salvador, 1994.

MONTEIRO, José Lemos. Pronomes Pessoais. Fortaleza: Edições UFC, 1994.

OMENA, Nelize Pires de. A referência à primeira pessoa do plural. In: SILVA, Giselle Machline de O.; SCHERRE, Maria Marta Pereira (Orgs.). Padróes Sociolingüísticos. Rio de Janeiro: Tempo Brasileiro, 1996. p. 185-215.

. As influências sociais na variação entre nós e a gente na função de sujeito. In:

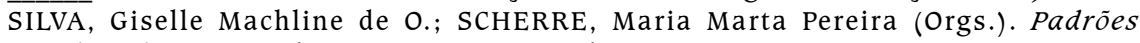
Sociolingüísticos. Rio de Janeiro: Tempo Brasileiro, 1996. p. 311-323. 
PAREDES DA SILVA, Vera Lúcia. Cartas Cariocas: a variação do sujeito na escrita informal. Boletim da Abralin, n. 11, p. 83-96, 1991.

SILVA, Maria Cristina Figueiredo. A Posição do Sujeito no Português Brasileiro - frases finitas e infinitivas. Campinas-SP: Editora da UNICAMP, 1996.

SILVA, Rita do Carmo Polli da. A elipse do sujeito pronominal em produções escritas. SEMINÁRIO DO GEL, 52, UNICAMP, Campinas, 2003b.

A expressão do tempo futuro: forma sintética $\mathrm{X}$ perífrases. In: Revista de Letras, n. 6, 2003a. Disponível em: <www.cefet.pr.br/deptos/dacex/rita6.htm>. 